\title{
Disease-inciting power of population of fungus Fusarium oxysporum (F. lini) on different by resistance grades of flux in conditions of North-East part of Ukraine
}

\author{
V. I. Chuchvaha, \\ Candidate of Biological Sciences \\ O. Yu. Yotka, \\ Candidate of Agricultural Sciences \\ L. M. Krivosheeva, \\ Candidate of Agricultural Sciences \\ I. V. Vereshchahin, \\ Candidate of Agricultural Sciences \\ National Academy Of Agrarian Sciences Of Ukraine \\ Institute of Bast Crops NAAS
}

The purpose. To study disease-inciting power of isolates of fungus Fusarium oxysporum (f. lini), secreted from grades of flux resistant and acquisitive to fusarial wilt. Methods. Vegetation, immunological, statistical. Results. Experimental data are given on study of the level of disease-inciting power of isolates of fungus Fusarium oxysporum (f. lini), secreted from grades of flux resistant and acquisitive to fusarial wilt. It is determined that isolates of fungus Fusarium oxysporum (f. lini), gained from grades resistant and acquisitive to disease caused their lesion with different extent of disease-inciting power. Conclusions. Isolates of fungus Fusarium oxysporum (f. lini), secreted from acquisitive grades of flux Svitoch and Tomskii 16, attack largely acquisitive grades and do not attack grades with high resistance I 7 and Aojagy. Isolates of fungus Fusarium oxysporum (f. lini), secreted from resistant grades I 7 and Aojagy, for years of researches have caused strong lesion of acquisitive to fusarial wilt grades Svitoch and Tomskii 16 as well as medium-acquisitive grades Hlinum and Charivnyi.

Key words: flux, fungus isolate, disease-inciting power.

Among the most dangerous diseases in the area of left-bank of Polissya of Ukraine is dominated by Fusarium. Its share in the pathogenic complex is $60-70 \%$. The local disease progression is observed every year, and the frequency of epifitotiynoho (losses of yield are more than $20 \%$ ) - five or six years of the twenty [1].

The main factors, causing the intensive development of Fusarium are a genetic vulnerability of agrobiocenosis and high aggressiveness of pathogens and lack of resistant varieties.

\section{Analysis of recent research and publications}

The effectiveness of selection on the immunity often depends on the availability of well-established source material and scientifically grounded approach to its use, and regular monitoring of pathogenic complex of pathogen [2].

Evaluation for resistance to diseases held at the population level, because the most valuable for breeding practices is a material, resistant to the entire population of the fungus. [3]

The feature of selection for resistance to diseases is that genotypes identified as a sources of stability, can quickly lose this status. This is due to changes of virulence of the pathogen in a particular region (the emergence of new, more aggressive races, cultures) and overcome their genetic systems to protect the culture.

This process depends on the speed of formation of the parasite races process, on the frequency of new mutations of it [4].

On pathogens with high ability of formation of the parasite races, the presence of the same resistance gene in the production of varieties are particularly dangerous, because this phenomenon is accelerating the evolution of the pathogen. 
Success of immunological method of protection products by selective depend on the availability of the genetic diversity of sources with effective resistance genes to virulence genes.

So important in this regard is the studying of the genetic structure of virulence of populations of the disease pathogen and a control of its change [5, 6].

Selection of agricultural crops against pathogens considered to be efficient and cost-effective means of plant protection.

In world practice, breeding for resistance to pathogens is held for a long time, which contributed to significant advances in the field of plant immunology and genetics of immunity. However, significantly increased the risk of genetic monotony of varieties with resistance genes. This happened because of widespread of varieties that stemped the varieties-population.

There are several ways to use the resistance genes, which are based selection program on immunity: creation of converged varieties, creation of multiline of varieties-populations, creation of varieties from polygenic resistance, creation of resistance transgenic varieties.

The ultimate goal of immunologists - creating the complex resistant varieties and development of genetic method of plant protection and introduce it as a leading system of measures to protect them. This is due to a genetic variability of well known pathogens and the spread under the pressure of anthropogenic factor of new races or species of pathogens. Established, that the resistance to phytopathogens depends on the genotype of two interacting organisms - the host and parasite. Resistant variety become susceptible when in the parasite population increased the frequency of virulence genes, complementary resistance genes that protect the variety. Also known that the larger the planting area of resistant variety, the greater the pressure of selection of the relevant virulence gene and the faster the resistant variety become the susceptible [7].

The purpose of research - studing the pathogenicity of isolates of the fungus F. oxysporum (f. Lini), which was isolated from resistant and susceptible varieties of long-flax fiber to Fusarium.

\section{Research Methods.}

Research conducted over the years 2012-2014. Collection of infectious material carried on the research areas of the Institute of Bast Crops NAAS. For this of susceptible varieties Svetoch and Tomskuy 16 in the phase of "tree" were affected plants. Then they were crushed, germinated in a moist chamber in Petri bowls and tested for the presence of mycelium by microscopic analysis.

By a similar scheme experiments were conducted with affected plants of resistant varieties as I 7 and Aojagy. Secretion of pathogen in a pure culture was carried out by conventional methods on artificial medium acidified potato agar $[8,9,10]$.

Inoculum was propagated on sterilized oat grains in flasks capacity of $250 \mathrm{ml}$ and after drying crushed on a laboratory mill. To achieve the same size of infectious particles, the powdered material was sieved through a sieve (hole diameter of $1 \mathrm{~mm}$ ).

To ensure the sufficient contact of seeds with the pathogen, inoculum was applied using adhesives, in this case the gelatinous mass formed during soaking flax seeds. The samples plated in vessels, 30 seeds in threefold repetition. Infection burden amounted of $0.25 \mathrm{~g}$ of crushed and ventilate inoculum to $100 \mathrm{~g}$ flax seeds. All experiments were conducted in greenhouse conditions.

Studing of pathogenicity of isolates of the fungus $F$. oxysporum (f. Lini) was performed at contrasting varieties of flax: Svetoch, Tomskuy 16 - susceptible to Fusarium; Hlinum, Charivnuy - medium susceptible to the pathogen, zoned; I 7, Aojagy - resistant.

\section{Results of research.}

Whatever the origin of the isolates of the fungus F. oxysporum (f. Lini), resulting from resistant or susceptible variety of flax, it caused lesions in all the varieties of flax, but it virulence was different for years. Thus, isolate of the fungus F. oxysporum (f. Lini), which was isolated from the susceptible variety Svetoch,lesioned the susceptible varieties: Svetoch within $73,2-78,4 \%$ and Tomskuy $16-69,9-81,3 \%$. Pathogenicity of isolate of Tomskuy 16 to Svetoch was at $63,8-88,1 \%$ for years and Tomskuy $16-74,2-83,4 \%$, and in the whole group of susceptible varieties $-70,8-82,8 \%$. In medium susceptible variety Charivnuy the lesions of plants by the same isolate was located within $47,8-57,2 \%$; Hlinum - $46,4-56,3 \%$ in the whole group of sustainability - $47,3-56,8 \%$, that less than of susceptible varieties. 
It should be noted that resistant varieties to Fusarium-I 7 and Aojagy had a very low percentage of lesions plants by isolate of the fungus isolated from the susceptible varieties. During the research the figure was within $17,4-19,2 \%$.

Based on the above we can conclude that isolates of the fungus F. oxysporum (f. Lini), which are isolated from susceptible varieties of flax, lesions in strong degree only the varieties of this group of stability and hardly affects a variety of high resistance group.

Isolates of the fungus $\mathrm{F}$. oxysporum (f. Lini), which were isolated from resistant varieties as Aojagy and I 7 for years the research caused severe destruction as susceptible to Fusarium varieties Svetoch and Tomskiy 16 (percentage of infected plants in the group of stability 91,6-94,4\%) and medium susceptible varieties Hlinum and Charivnuy (the percentage of infected plants in the group of stability $74,2-74,8 \%$ ). Resistant varieties 17 and Aojagy found resistance above the average level for this pathogen isolates (percentage of infected plants was for years of studing 48,1-69,6\%).

Differ by pathogenicity the isolates of the fungus F. oxysporum (f. Lini), isolated from different varieties of the same group of resistance to Fusarium. Thus, the power of pathogenic isolate from a variety Aojagy (group of resistant varieties) was for years a little larger than I 7. And if the index of lesions by Fusarium regardless of variety by isolate Aojagy located within $47,2 \pm 1,8-99,3 \pm 4,2$ so I $7-43,4 \pm 1,7-92,6 \pm 4,2 \%$.

Similarly, there is a regularity in relation of fungus isolates, isolated from the susceptible varieties Tomskuy 16 and Svetoch. Isolate of variety Tomskuy 16 lesioned flax plant by disease within 16,6 $\pm 0,6-88,1 \pm 3,6 \%$, Svetoch slightly less $-14,9 \pm 0,6-81,3 \pm 3,5 \%$.

The pathogenicity of all isolates of the fungus Fusarium oxysporum (f.lini) in respect to a particular variety of flax virtually unchanged for years.

Thus, the isolate of Aojagy against the Charivnuy caused lesions in $2012-77,5 \pm 3,2 \%$, in $2013-77,5 \pm$ $3,5 \%$, in $2014-75,9 \pm 3.6 \%$, relative to Svetoch - accorgingly $89,1 \pm 3,8 ; 97,8 \pm 4,1$ and $99,3 \pm 4,2 \%$. The isolate of Tomskuy16 against the Charivnuy caused lesions by years: $2012-42,7 \pm 1,7 ; 2013-34,9 \pm 1,4$ and in $2014-51,3 \pm 2,0 \%$; relative to Svetoch $-88,1 \pm 3,6 ; 83,7 \pm 3,4$ and $63,8 \pm 2,7 \%$.

So, while growing the resistant varieties of flax to Fusarium naturally formed in the wild the new populations of disease with a wide spectrum of pathogenicity. 
1. Pathogenicity of populations of Fusarium oxysporum $\mathrm{f}$. lini, isolated from various resistant varieties of flax to Fusarium

\begin{tabular}{|c|c|c|c|c|c|c|}
\hline \multirow{2}{*}{ Origin of Fusarium oxysporum $f$. lini } & \multicolumn{6}{|c|}{ The degree of lesion of plant varieties, $\%$} \\
\hline & 17 & Aojagy & Charivnuy & Hlinum & Svetoch & Tomskiy16 \\
\hline \multicolumn{7}{|l|}{$2012 \mathrm{p}}$. \\
\hline Isolate of Aojagy & $53,4 \pm 2,1$ & $47,2 \pm 1,8$ & $77,5 \pm 3,2$ & $79,4 \pm 3,6$ & $89,1 \pm 3,8$ & $93,1 \pm 4,5$ \\
\hline Isolate of I 7 & $48,1 \pm 2,0$ & $43,4 \pm 1,7$ & $69,3 \pm 2,9$ & $72,8 \pm 3,0$ & $91,6 \pm 4,3$ & $92,4 \pm 4,5$ \\
\hline $\bar{X}$ & $50,8 \pm 2,1$ & $45,3 \pm 1,8$ & $73,4 \pm 3,0$ & $76,1 \pm 3,3$ & $90,4 \pm 4,1$ & $92,8 \pm 4,5$ \\
\hline$\overline{\bar{X}}$ the resistant group & \multicolumn{2}{|l|}{$48,1 \pm 2,0$} & \multicolumn{2}{|l|}{$74,8 \pm 3,2$} & \multicolumn{2}{|l|}{$91,6 \pm 4,3$} \\
\hline Isolate of Tomskiy16 & $20,4 \pm 0,8$ & $17,2 \pm 0,7$ & $42,7 \pm 1,7$ & $39,4 \pm 1,6$ & $88,1 \pm 3,6$ & $83,4 \pm 3,5$ \\
\hline Isolate of Svetoch & $17,6 \pm 0,7$ & $16,1 \pm 0,6$ & $58,6 \pm 2,3$ & $53,4 \pm 2,0$ & $78,4 \pm 3,2$ & $81,3 \pm 3,5$ \\
\hline $\bar{X}$ & $19,0 \pm 0,8$ & $16,7 \pm 0,6$ & $50,7 \pm 2,0$ & $46,4 \pm 1,8$ & $83,3 \pm 3,4$ & $82,4 \pm 3,5$ \\
\hline $\bar{X}$ the resistant group & \multicolumn{2}{|l|}{$17,8 \pm 0,7$} & \multicolumn{2}{|l|}{$48,6 \pm 1,9$} & \multicolumn{2}{|l|}{$82,8 \pm 3,4$} \\
\hline \multicolumn{7}{|l|}{$2013 \mathrm{p}$} \\
\hline Isolate of Aojagy & $82,1 \pm 3,4$ & $73,1 \pm 3,3$ & $77,5 \pm 3,5$ & $76,3 \pm 3,5$ & $97,8 \pm 4,1$ & $94,6 \pm 3,9$ \\
\hline Isolate of I 7 & $63,6 \pm 2,7$ & $58,7 \pm 2,4$ & $69,4 \pm 2,8$ & $73,3 \pm 3,2$ & $88,7 \pm 4,2$ & $92,6 \pm 4,5$ \\
\hline $\bar{X}$ & $72,9 \pm 3,0$ & $65,9 \pm 2,8$ & $73,5 \pm 3,2$ & $74,8 \pm 3,4$ & $93,3 \pm 4,2$ & $93,6 \pm 4,7$ \\
\hline
\end{tabular}




\begin{tabular}{|c|c|c|c|c|c|c|}
\hline \multirow{2}{*}{ Origin of Fusarium oxysporum f. Lini } & \multicolumn{6}{|c|}{ The degree of lesion of plant varieties, $\%$} \\
\hline & 17 & Aojagy & Charivnuy & Hlinum & Svetoch & Tomskiy16 \\
\hline $\bar{X}$ the resistant group & \multicolumn{2}{|l|}{$69,6 \pm 2,9$} & \multicolumn{2}{|l|}{$74,2 \pm 3,3$} & \multicolumn{2}{|l|}{$93,5 \pm 4,4$} \\
\hline Isolate of Tomskiy16 & $19,7 \pm 0,8$ & $16,6 \pm 0,6$ & $34,9 \pm 1,4$ & $35,1 \pm 1,4$ & $83,7 \pm 3,4$ & $81,1 \pm 3,2$ \\
\hline Isolate of Svetoch & $19,2 \pm 0,7$ & $21,1 \pm 0,9$ & $60,7 \pm 2,5$ & $58,4 \pm 2,4$ & $73,2 \pm 2,9$ & $80,3 \pm 3,1$ \\
\hline $\bar{X}$ & $19,5 \pm 0,8$ & $18,9 \pm 0,8$ & $47,8 \pm 1,9$ & $46,8 \pm 1,9$ & $78,5 \pm 3,2$ & $80,7 \pm 3,2$ \\
\hline $\bar{X}$ the resistant group & \multicolumn{2}{|l|}{$19,2 \pm 0,8$} & \multicolumn{2}{|l|}{$47,3 \pm 1,9$} & \multicolumn{2}{|l|}{$79,6 \pm 3,2$} \\
\hline \multicolumn{7}{|l|}{$2014 \mathrm{p}$} \\
\hline Isolate of Aojagy & $51,2 \pm 2,2$ & $63,4 \pm 3,0$ & $75,9 \pm 3,6$ & $81,1 \pm 3,9$ & $99,3 \pm 4,2$ & $97,6 \pm 4,2$ \\
\hline Isolate of I 7 & $47,1 \pm 2,2$ & $52,4 \pm 2,4$ & $69,7 \pm 3,5$ & $72,4 \pm 3,4$ & $91,6 \pm 4,0$ & $88,9 \pm 3,8$ \\
\hline $\bar{X}$ & $49,2 \pm 2,2$ & $57,9 \pm 2,7$ & $72,8 \pm 3,5$ & $76,8 \pm 3,6$ & $95,5 \pm 4,1$ & $93,3 \pm 4,0$ \\
\hline $\bar{X}$ the resistant group & \multicolumn{2}{|l|}{$53,6 \pm 2,4$} & \multicolumn{2}{|l|}{$74,8 \pm 3,6$} & \multicolumn{2}{|l|}{$94,4 \pm 4,0$} \\
\hline Isolate of Tomskiy16 & $19,2 \pm 0,8$ & $18,7 \pm 0,8$ & $51,3 \pm 2,0$ & $47,4 \pm 1,9$ & $63,8 \pm 2,7$ & $74,2 \pm 3,1$ \\
\hline Isolate of Svetoch & $14,9 \pm 0,6$ & $16,8 \pm 0,7$ & $63,1 \pm 2,5$ & $65,1 \pm 2,7$ & $75,3 \pm 3,3$ & $69,9 \pm 3,0$ \\
\hline $\bar{X}$ & $17,1 \pm 0,7$ & $17,8 \pm 0,8$ & $57,2 \pm 2,2$ & $56,3 \pm 2,3$ & $69,6 \pm 3,0$ & $72,1 \pm 3,0$ \\
\hline $\bar{X}$ the resistant group & \multicolumn{2}{|l|}{$17,4 \pm 0,8$} & \multicolumn{2}{|l|}{$56,8 \pm 2,3$} & \multicolumn{2}{|l|}{$70,8 \pm 3,0$} \\
\hline
\end{tabular}




\section{Conclusions}

Isolates of the fungus Fusarium oxysporum (f.lini), which are marked from susceptible varieties of flax Svetoch and Tomskuy 16 affects the varieties in great extent only that resistant group and hardly affects the varieties of high resistance-I 7 and Aojagy.

Isolates of the fungus Fusarium oxysporum (f. Lini), which are isolated of resistant varieties as I 7 and Aojagy caused the severe lesion as susceptible varieties to Fusarium as Svetoch and Tomskuy 16 so medium susceptible varieties as Hlinum and Charivnuy.

This fact points to the need of studying the variability of the populations of the fungus Fusarium oxysporum (f. Lini) and establishing among them the most pathogenic and used in breeding work in the creation of artificial infectious backgrounds.

\section{Bibliography}

1. Chuchvaha V.I. Inheritance of the stability of flax to Fusarium wilt. Selection, cultivation technology, cleaning and primary processing of hemp: coll. scientific. p. VNYYLK. Hlukhov, 1989. P. 50-54.

2. Kutuzova S.N., Porohovinova Ye.A., Brach N.B. Variation in the virulence of the rust flax population of Melpanora lini (Pers) Lev. in the North-West of Russia. Genetic basis of ecosystem evolution. 2015. Volume XIII, №3. P. 50-61.

3. Rozhmina T.A. Loshakova N.I. Samples of spinning and oil flax (Linum usitatissimum L.) - sources of effective genes of resistance to fusarium wilt and its dependence on temperature. Agricultural biology. 2016. Vol. 51, №3. P. 310-317.

4. Loshakova N.I., Kudryavtseva L.P., Pavlova L.N., Rozhmyna T.A. The role of the collection of phytopathogenic organisms - pathogens of flax diseases in breeding for group resistance to diseases. Oilseeds. Scientific and Technical Bulletin of the All-Russian Research Institute of Oilseeds. 2011. Issue 2. P. 159-160.

5. Polonetskaya L.M. Portyankin D.E., Sakovich V.I.Genetic analysis of components of productivity and resistance to Fusarium wilt in Fiber flax in diallel crossing system. Bast Fibrous today and tomorrow. St. Petersburg, 1998. P. 141-143.

6. Karpunin B.F. Anthracnose of flax: selection for stability. Genetics, selection of source material, tactics and methodology of selection for sustainability: monograph. Deutshland: Lambert Academic Publishin, 2016. $117 \mathrm{p}$.

7. Lisovuy M.P., Lisova H.M. The reasons for the loss of varieties resistance to pathogens and ways to prevent it. Protection and quarantine of plants. 2009. Issue 55. P. 145-157.

8. Kiray Z., Klement W., Shoymoshy I. Methods of plant pathology. Moscow: Kolos, 1974. 343 p.

9. Loshakova N.I., Krylova T.V., Kudryavtseva L.N. Methodological guidelines on the phytopathological assessment of the resistance of flax fiber to disease. Moscow: VNII of flax, 2000. $52 \mathrm{p}$.

10. Chuchvaha V.I., Loginov M.I. Guidelines for the Phytopathological assess of the stability of breeding material of flax to Fusarium. Sumy: Note Bene, 2007. 11 p. 